\title{
Using a Genome-Based PCR Primer Prediction Pipeline to Develop Molecular Diagnostics for the Turfgrass Pathogen Acidovorax avenae
}

Paul R. Giordano, Jie Wang, Joseph M. Vargas, Janette Jacobs, and Martin I. Chilvers, ${ }^{\dagger}$ Department of Plant, Soil and Microbial Sciences, Michigan State University, East Lansing, 48824; and Quan Zeng, ${ }^{\dagger}$ Department of Plant Pathology and Ecology, The Connecticut Agricultural Experiment Station, New Haven 06511

\begin{abstract}
Acidovorax avenae is the causal agent of bacterial etiolation and decline (BED) of creeping bentgrass, a poorly understood and often misdiagnosed disease that can result in considerable aesthetic and functional damage to golf course putting greens. Current diagnostics of BED are based on laborious culture-based methods. In this work, we employed a novel alignment-free primer prediction pipeline to design diagnostic primers for turfgrass-pathogenic A. avenae using $15 \mathrm{draft}$ genomes of closely related target and nontarget Acidovorax spp. as input. Twenty candidate primer sets specific to turfgrass-pathogenic A. avenae were designed. The specificity and sensitivity of these primer sets were validated via a traditional polymerase chain reaction (PCR) and

a real-time PCR assay. Primer sets 0017 and 0019 coupled with an internal oligo probe showed optimal sensitivity and specificity when evaluated with the target pathogen, closely related bacterial species, and microorganisms that inhabit the same host and soil environment. Finally, the accuracy of the newly developed real-time PCR assay was evaluated to detect BED pathogens from BED-symptomatic and asymptomatic turfgrass samples. The diagnostic results produced by the real-time PCR assay were consistent with results of a cultural-based method. This assay will allow quicker and more effective detection of the BED pathogen, thus potentially reducing misdiagnoses and unnecessary usage of fungicides.
\end{abstract}

Acidovorax avenae is the causal agent of bacterial etiolation and decline (BED), a serious disease of creeping bentgrass (Agrostis stolonifera L.) on golf course putting greens (Giordano et al. 2010, 2012; Roberts et al. 2018). Often associated with high summer temperature $\left(>30^{\circ} \mathrm{C}\right)$, symptoms of this disease appear as irregularshaped areas of foliar discoloration and stem and blade etiolation, followed by thinning and necrosis of the foliar canopy. First identified in 2009, BED has been consistently detected on golf courses around the United States, including mid-Atlantic, Midwest, and northeastern states, leading to substantial economic losses (Giordano et al. 2012).

Early, accurate diagnosis of BED can lead to proper management recommendations and avoid unnecessary and ineffective fungicide treatments (Sundin et al. 2016). Although an effective management option for BED has yet to be developed, early diagnosis of BED can avoid the misdiagnosis of BED as a fungal disease and, thus, avoid the misuse of fungicides. A recent report by Roberts et al. (2016) revealed that some plant growth regulators show promise in the management of BED.

Accurate diagnosis of BED has been confounded by several factors. First, bacterial diseases on turfgrass are rare. Only a few other

Present address of P. R. Giordano: Division of Environmental Science, Bayer CropScience LP, Guelph, Ontario, Canada.

Present address of J. Wang: Department of Plant Biology, Michigan State University, East Lansing 48824

${ }^{\dagger}$ Corresponding authors: Martin I. Chilvers; E-mail: chilvers@msu.edu; and Quan Zeng; E-mail: quan.zeng@ct.gov

P. R. Giordano and J. Wang contributed equally to this work.

Funding: This research was supported by the United States Department of Agriculture National Institute of Food and Agriculture Hatch Grant (CONH00650) to Q. Zeng and by the United States Golf Association Green Section Research to P. R. Giordano. The funders had no role in study design, data collection and analysis, decision to publish, or preparation of the manuscript.

Accepted for publication 23 April 2018.

C 2018 The American Phytopathological Society major diseases of turfgrass are caused by bacterial pathogens on annual bluegrass (Pоа апnи L L.) and perennial ryegrass (Lolium perenne), known as bacterial wilt caused by Xanthomonas translucens (Giordano et al. 2015; Mitkowski et al. 2005); thus, turfgrass diagnosticians are typically not adequately equipped for the identification of bacterial pathogens. Second, Acidovorax pathogens are often seedborne (Gitaitis and Walcott 2007; Goto 1964; Shakya and Chung 1983; Walcott and Gitaitis 2000) and, although this has not been confirmed in creeping bentgrass, the pathogen does not always produce distinct symptoms under field conditions. The disease is often very difficult to diagnose and, in such cases, diagnosis must rely on timeconsuming isolation and pathogenicity testing. Finally, the turfgrasspathogenic Acidovorax avenae is genetically closely related to other plant-pathogenic members of the Acidovorax genus, including A. citrulli, A. cattleyae, A. facilis, and A. konjaci (Walcott et al. 2000). Even within A. avenae spp., different strains are able to infect different graminaceous hosts, including rice, maize, sorghum, foxtail, and so on, displaying a range of host specificity (Postnikova and Schaad 2002; Stead et al. 2003; Zeng et al. 2017). Our recent study revealed that two distinct phylogroups of turfgrass-pathogenic A. avenae strains were equally able to cause the BED symptoms, and both groups are closely related to $A$. avenae strains pathogenic to other graminaceous hosts (Zeng et al. 2017).

Real-time quantitative polymerase chain reaction (real-time PCR) has been widely used in detection and quantification of plant pathogens (López et al. 2010; Pritchard et al. 2012b; Wang et al. 2015). The ability to rapidly amplify and sensitively detect a pathogen DNA by real-time PCR allows diagnosticians to provide definitive diagnostic results within one working day (Schena et al. 2004). The ability of real-time PCR to deliver sensitive and quantifiable results is dependent on the availability of primer sets that distinguish a target organism or organisms from nontarget organisms (Pritchard et al. 2012a). The design of discriminatory primer sets is typically guided by common sequences in the target organisms that are divergent, or absent, in nontarget organisms. The most commonly used sequences include internal transcribed spacer (ITS) regions, ribosomal DNA (rDNA), "housekeeping" genes, and virulence genes (Grisham et al. 2007; Schaad et al. 2002, 2007). Diagnostic amplification of DNA from members of the Acidovorax genus by conventional PCR has been largely based on the sequence of the 16S-23S rDNA, ITS (Song et al. 2002), or unique DNA fragments from profiles using repetitive extragenic palindromic (rep)-PCR (Song et al. 
2004; Walcott et al. 2004). Primers have been described for many plant-pathogenic bacteria, including Acidovorax at the genus level (Bahar et al. 2008); however, the Acidovorax-specific primers tend to amplify all species and subspecies of Acidovorax, and are not specific to strains pathogenic only to grass species, particularly turfgrass (Bahar et al. 2008).

Although many bioinformatic tools have been developed to design PCR primers for diagnosis of bacterial pathogens, most of them utilize DNA sequences of individual genes as input and predict primers that differentiate target strains from others based on the sequence divergence. This significantly limits the selection of primers as well as their sensitivity and specificity. In this study, we utilized a bioinformatic pipeline that identifies primers at the genome level. Using the 15 draft genomes of turfgrass-pathogenic and other host-pathogenic Acidovorax strains as input, we successfully predicted primers that only amplify the turfgrass-pathogenic A. avenae strains but not other closely related strains. The specificity and sensitivity of two predicted primer sets were experimentally validated against a panel of Acidovorax strains. Employing real-time PCR and conventional PCR assays with primer sets developed herein, we were able to clearly differentiate the turfgrass-pathogenic A. avenae from other Acidovorax strains pathogenic to other hosts, and microorganisms that inhabit the same host and environment, with excellent sensitivity, specificity, and rapidity. The molecular methods refined in this study will not only allow for a tool to detect and diagnose infection by the pathogen but also will be useful in ecological studies of the bacterium (i.e., to determine when and where the pathogen proliferates under certain environmental conditions).

\section{Materials and Methods}

Bacterial strains and genomes. Turfgrass-pathogenic A. avenae isolates were obtained from creeping bentgrass (Agrostis stolonifera L.) and colonial bentgrass (A. capillaris L.) samples with BED symptoms sent to Michigan State University and the University of Rhode Island turfgrass diagnostic laboratories between 2009 and 2012. The pathogenicity of all Acidovorax avenae strains was confirmed by inoculating creeping bentgrass cups as described (Giordano et al. 2012). All other Acidovorax isolates from different hosts were obtained from Dr. Ron Walcott at the University of Georgia. Other grass-associated bacteria such as Ochrobactrum pseudogrignonense, Microbacterium binotii, Stenotrophomonas maltophilia, Herbaspirillum seropedicae, and X. translucens were isolated by the Michigan State University turfgrass diagnostic laboratory from turfgrass samples of golf courses. Bacteria were cultured

Table 1. Acidovorax genomes used in this study ${ }^{\mathrm{a}}$

\begin{tabular}{lcccc}
\hline Strain & 16S rDNA identification & NCBI accession & Host of origin & Source \\
\hline AA78-5 & Acidovorax avenae & CP028287 & Maize & Ha et al. 2009 \\
AA99-2 & A. avenae & CP028289 & Maize & Ha et al. 2009 2009 \\
CAT98-1 & A. cattleyae & CP028290 & Orchid & Zeng et al. 2017 \\
COLB1 & A. avenae & CP028291 & Creeping bentgrass & Zeng et al. 2017 \\
INDB2 & A. avenae & CP028292 & Creeping bentgrass & Zeng et al. 2017 \\
INV & A. avenae & CP028293 & Creeping bentgrass & Zeng et al. 2017 \\
KL3 & A. avenae & CP028294 & Creeping bentgrass & Zeng et al. 2017 \\
MDB1 & A. avenae & CP028296 & Creeping bentgrass & Zeng et al. 2017 \\
MOR & A. avenae & CP028297 & Creeping bentgrass & Zeng et al. 2017 \\
NCT3 & A. avenae & CP028298 2017 \\
QH1 & A. avenae & CP028299 & Creeping bentgrass & Zeng et al. 2017 \\
QHB1 & A. avenae & CP028300 & Creeping bentgrass & Zeng et al. 2017 \\
SF12 & A. avenae & CP028302 & Creeping bentgrass & Ceng et al. 2017 \\
SH7 & A. avenae & CP028303 & Creeping bentgrass & Zeng et al. 2017 \\
SA2 & A. avenae & CP028301 &
\end{tabular}

${ }^{a}$ rDNA = ribosomal DNA and NCBI = National Center for Biotechnology Information.

Table 2. Twenty polymerase chain reaction primer sets predicted by the primer prediction pipeline that can distinguish turfgrass-pathogenic Acidovorax avenae strains $^{\mathrm{a}}$

\begin{tabular}{|c|c|c|}
\hline Set name & Forward primer $\left(5^{\prime}-3^{\prime}\right)$ & Reverse primer $\left(5^{\prime}-3^{\prime}\right)$ \\
\hline 001 & GCATGGAAATGCACGTAGAG & GCTGAAGCAGTACCCTTTCC \\
\hline 002 & ATCGATGTGATCACCTGTGG & TTCTTCGTCGCATAACGAAC \\
\hline 003 & TCACCTACACTCTGGCGAAG & GTGGAAGGGTGACGAGACTT \\
\hline 004 & GGTAGCACGACTCCACCTCT & ATGGAACTCTTCAGGGCAGT \\
\hline 005 & GCCATATCGCAAGAATTGTG & TTAGCCCAAATCAGCAACTG \\
\hline 006 & TTTGACGCTTTGTTCGAGTC & CCTCGACTTCCAAGTTCACA \\
\hline 007 & AGATTAGGCGACGGTTGAGT & GGTGCCTCTTATGGGTGATT \\
\hline 008 & TTTGACGCTTTGTTCGAGTC & CGACTTCCAAGTTCACATGC \\
\hline 009 & CATGGAAATGCACGTAGAGC & GCTGAAGCAGTACCCTTTCC \\
\hline 0010 & TAGAGCGCTTGCTGGTAGTG & ATCCTATGCCAACAGCACAG \\
\hline 0011 & ACCGAAGAGAAGGTCGTCAC & CGACGATCCAGATCACGTAG \\
\hline 0012 & AGAGAAGGTCGTCACCATCC & CGACGATCCAGATCACGTAG \\
\hline 0013 & CCAAGTTCACATGCTCCAAT & CCGGTACTTTGACCCTTTGT \\
\hline 0014 & CTGGAACGCTCTGATGAAGA & AGAGCTTCACACGATTCACG \\
\hline 0015 & CCTTCGTTGTGTTTCTGGTG & GCCATGAGCATGTAGCTGTT \\
\hline 0016 & TTTGACGCTTTGTTCGAGTC & ACCTCGACTTCCAGGTTCAC \\
\hline 0017 & GCGCAAAGATGTAGGTTTGA & AGTCCGCCCAATACGATTAC \\
\hline 0018 & TTGGAGCAACGAATGATTTC & TTCAACGGTGTATTGCCATT \\
\hline 0019 & GGAGCGCAAAGATGTAGGTT & AGTCCGCCCAATACGATTAC \\
\hline 0020 & CCGGTACTTTGACCCTTTGT & GCTTCCAAGTTCACATGCTC \\
\hline
\end{tabular}

a Primer sequences were predicted by the pipeline, and used in validation assays for the detection of turfgrass-pathogenic strains of Acidovorax avenae. Predicted primers in the table include nonredundant pairs with desired specificity selected from the complete set of predicted primers. 
in King's B medium (King et al. 1954) and stored at $-80^{\circ} \mathrm{C}$ in $15 \%$ of glycerol.

Genomes of 15 strains of Acidovorax spp. were acquired from the National Center for Biotechnology Information genome database. This includes 12 strains of $A$. avenae isolated from naturally infected creeping bentgrass (Agrostis stolonifera L.), 2 Acidovorax avenae strains from maize, and $1 \mathrm{~A}$. cattleyae strain isolated from orchid (Table 1). These genomes were used as input in the primer prediction pipeline.

Primer prediction pipeline. The primer design pipeline was adopted from Pritchard et al. (2012a), with minor adjustments for the purpose of this study. A comprehensive description of the methodology can be found in the supplementary materials of Pritchard et al. (2012a). Briefly, a configuration file specifying the location of input sequences of each isolate in FASTA format, and the species classification of that isolate, was provided to the primer design script (available for download at https://github.com/widdowquinn/find differential_primers). A single pseudochromosome was compiled for the set of draft contigs belonging to each isolate. Prediction of coding sequences was carried out on the pseudochromosome using PRODIGAL, version 2.6 (Hyatt et al. 2010), where necessary. In total, 20,000 primer sets were predicted for each isolate

Table 3. Polymerase chain reaction amplification from target and nontarget bacterial isolates grouped by primer set at the optimized primer annealing temperature $\left(64^{\circ} \mathrm{C}\right)$

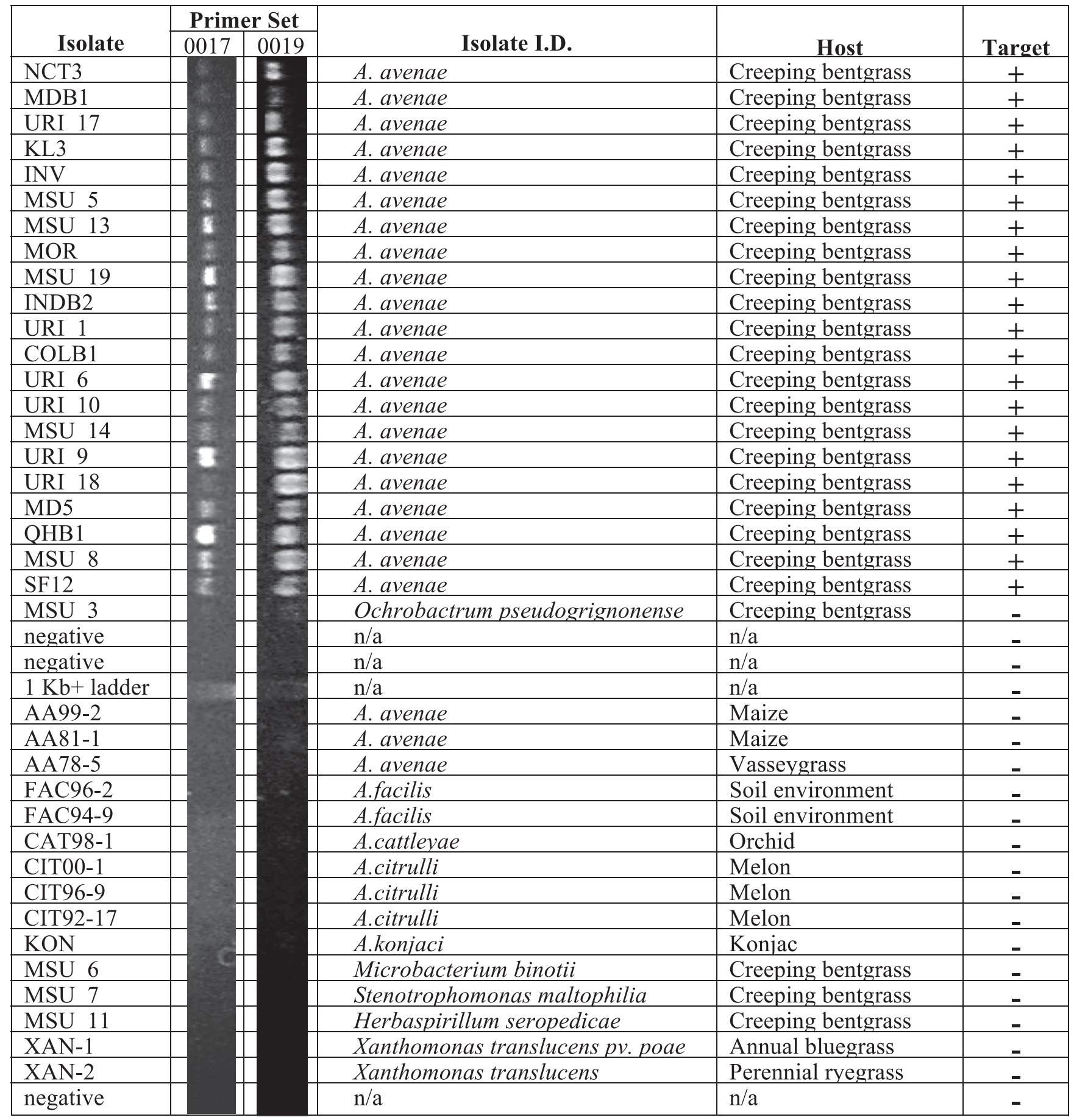

Images are from agarose gels that have been aligned against the matching isolate designation (leftmost column) and below the primer names (top row). The image is split so that target isolates of turfgrass-pathogenic Acidovorax avenae are located in the top section. The bottom section includes several different nontarget Acidovorax spp. as bacterial organisms isolated from the turfgrass phyllosphere and rhizosphere, including two pathogenic Xanthomonas spp. The two sections are bound by a $1-\mathrm{kb}+$ ladder. Both primer sets show results after optimization of annealing temperature at $64^{\circ} \mathrm{C}$ during thermal cycling. 
pseudochromosome using EPRIMER3 (Rice et al. 2000), keeping only the primer sets that exist entirely within a predicted coding sequence. PRIMERSEARCH (Rice et al. 2000) was used to identify cross-amplification of each isolate. A filter for off-target amplification was implemented by querying primer sets against sequenced Enterobacteriaceae and other $\beta$-Proteobacteria (but not Acidovorax) genomes using BLASTN. Primer sets were classified according to their ability to amplify host (turfgrass)-specific Acidovorax spp. The results were written to a summary output file. Commands and configuration files used in this study were deposited to GitHub (https://github.com/wjidea/AVX_Diagnostic_Find_Primers). Thermodynamics specified for amplification primers during the prediction phase included a $T_{m}$ (melting temperature) between 58 and $60^{\circ} \mathrm{C}\left(59^{\circ} \mathrm{C}\right.$ optimal $)$ and a GC content of 30 to $80 \%$, with no more than two $\mathrm{G}+\mathrm{C}$ in the last five nucleotides of the $3^{\prime}$ end. During the prediction process, runs of identical nucleotides were avoided, and sequence constraints were applied to design sets of amplicons of 150 to $250 \mathrm{bp}$ in length. Primer sets contained flanking primer sequences only, or flanking primer sequences and an internal oligomer for postamplification hybridization. Hybridization probes were specified to have a length of 13 to $30 \mathrm{bp}$ with a $T_{m}$ between 68 and $70^{\circ} \mathrm{C}$. Nonredundant, putative turfgrass-pathogenic $A$. avenae-specific primer sets are listed in Table 2.

Primer evaluation in conventional PCR. Seven bacterial isolates were first screened with each of the 20 putative specific primer sets: two target isolates of $A$. avenae COLB1 and URI1 and five nontarget isolates, including A. avenae AA81-1 and AA99-2 (nontarget $A$. avenae), A. cattleyae CAT98-1 (nontarget Acidovorax sp.), A. citrulli CIT00-1 (nontarget Acidovorax sp.), A. konjaci KON (nontarget Acidovorax sp.), and X. translucens pv. poae PAR5 (nontarget turf pathogen). Once screened, primers with specificity to the target turfgrass isolates were further tested against a broader range of target and nontarget bacterial isolates (Tables 1 and 3). Prior to all experiments, bacteria were grown on King's B medium and DNA was extracted using the DNeasy Blood and Tissue Kit (Qiagen) according to the manufacturer's protocol. PCR of $25 \mu \mathrm{l}$ contained DNA template at 5 to $20 \mathrm{ng} / \mu \mathrm{l}, 0.2 \mu \mathrm{M}$ final concentration of each primer, and $12.5 \mu$ l of a $2 \times$ MeanGreen PCR Master Mix (Syzygy Biotech). Annealing temperature was set to $60^{\circ} \mathrm{C}$ due to the proposed optimal annealing temperature for each primer being predicted near $60^{\circ} \mathrm{C}$ by the pipeline. Standard cycling conditions included 1 cycle at $94^{\circ} \mathrm{C}$ for $5 \mathrm{~min} ; 30$ cycles of $94^{\circ} \mathrm{C}$ for $30 \mathrm{~s}, 60^{\circ} \mathrm{C}$ for $1 \mathrm{~min}$, and $72^{\circ} \mathrm{C}$ for $1 \mathrm{~min}$; and 1 cycle of $72^{\circ} \mathrm{C}$ for $5 \mathrm{~min}$. Products were resolved on a $1 \%$ agarose gel in Tris-borate-EDTA buffer at $0.5 \times$ concentration, alongside a 1-kb+ ladder (Life Technologies). The images were captured under standard conditions in a gel documentation system at $300 \mathrm{dpi}$ and saved in TIFF format. Image manipulations (combination of multiple gel results into single figures) were carried out using Adobe Illustrator.

Further conventional PCR assay optimization was carried out with selected primer sets $(0003,0010,0017$, and 0019) utilizing a gradient range of annealing temperatures. Briefly, $10 \mathrm{ng}$ of genomic DNA from target (QHB1, COLB1, MSU14, and MOR) and nontarget (AA78-5, CAT98-1, CIT00-1, and FAC96-2) isolates was used in PCR preparations according to the aforementioned protocol. The PCR was run using a gradient of four annealing temperatures (58, 60,64 , and $66^{\circ} \mathrm{C}$ ) using the following cycling conditions on an Eppendorf Mastercycler nexus thermal cycler: initial denaturing at $94^{\circ} \mathrm{C}$ for $90 \mathrm{~s}$; followed by 35 cycles of $94^{\circ} \mathrm{C}$ denaturing for $15 \mathrm{~s}$, gradient temperature $\left({ }^{\circ} \mathrm{C}\right)$ annealing for $20 \mathrm{~s}$, and $72^{\circ} \mathrm{C}$ extension for 30 $\mathrm{s}$; with a final cycle of $72^{\circ} \mathrm{C}$ for $7 \mathrm{~min}$. Gel electrophoresis and band imaging were performed as mentioned above. Further testing of all target and nontarget isolates on hand was carried out with the primer sets 0017 and 0019 and performed under the protocol described above with the selected annealing temperature of $64^{\circ} \mathrm{C}$ during PCR thermal cycling.

Real-time PCR evaluation. Two primer sets (0017 and 0019) with specificity to turfgrass-pathogenic $A$. avenae via conventional PCR were selected for further evaluation in real-time PCR assay development. The Primer Express 3.0 software (Applied Biosystems) was used for the TaqMan probe design. Candidate probe sequences were queried against the GenBank database for Enterobacteriaceae using BLASTN as well as the genomic sequences derived in this study, and A. avenae-specific oligonucleotides were selected. The TaqMan probe 6FAM-TACGGGTACGCCCACAA-MGBNFQ was synthesized by Life Technologies (http://www.thermofisher. $\mathrm{com} /$ ) and consists of a minor DNA groove-binding quencher. The ZEN probe 6FAM-ACCGTCGCTTACCATCACCGTAGATTC

Table 4. Detection of turfgrass-pathogenic Acidovorax avenae with designed primers and probes from frozen and fresh turfgrass samples

\begin{tabular}{|c|c|c|c|c|c|c|c|}
\hline \multirow[b]{3}{*}{ Sample } & \multicolumn{4}{|c|}{$\begin{array}{l}\text { Real-time PCR results for primer sets } \\
\text { and probe types }\end{array}$} & \multirow[b]{3}{*}{ Sample description } & \multirow[b]{3}{*}{ Host } & \multirow[b]{3}{*}{ Isolation $^{\mathbf{b}}$} \\
\hline & \multicolumn{2}{|c|}{0017} & \multicolumn{2}{|c|}{0019} & & & \\
\hline & TaqMan & ZEN & TaqMan & ZEN & & & \\
\hline HTRC_2012 & $25.7(+)$ & $24.6(+)$ & $23.9(+)$ & $23.5(+)$ & $\begin{array}{l}\text { Research plot, putting green turf, inoculated with } \\
\text { turfgrass-pathogenic A. avenae, etiolation, streaming } \\
(+), \text { frozen }\end{array}$ & Creeping bentgrass & + \\
\hline HTRC_2013 & $19.6(+)$ & $19.2(+)$ & $18.5(+)$ & $20.6(+)$ & $\begin{array}{l}\text { Research plot, putting green turf, inoculated with } \\
\text { turfgrass-pathogenic A. avenae, etiolation, streaming } \\
(+) \text {, frozen }\end{array}$ & Creeping bentgrass & + \\
\hline LVL12 & $20.4(+)$ & $19.8(+)$ & $18.9(+)$ & $21.7(+)$ & $\begin{array}{l}\text { Golf course, putting green turf, etiolation, decline, } \\
\text { streaming }(+) \text {, frozen }\end{array}$ & Creeping bentgrass & + \\
\hline IL_HIN & $22.0(+)$ & $21.4(+)$ & $20.8(+)$ & $22.4(+)$ & $\begin{array}{l}\text { Golf course, putting green turf, etiolation, decline, } \\
\text { streaming }(+) \text {, frozen }\end{array}$ & Creeping bentgrass & + \\
\hline GLET10 & $37.4(-)$ & $37.1(-)$ & $38.8(-)$ & ND (-) & $\begin{array}{l}\text { Golf course, putting green turf, etiolation, streaming }(-) \text {, } \\
\text { frozen }\end{array}$ & Creeping bentgrass & - \\
\hline BNTSD1 & $37.5(-)$ & $37.2(-)$ & $37.6(-)$ & ND (-) & $\begin{array}{l}\text { 5-week-old seedlings, greenhouse grown, no } \\
\text { symptoms, streaming }(-) \text {, fresh }\end{array}$ & Creeping bentgrass & - \\
\hline GLNRM & $37.0(-)$ & $36.9(-)$ & $38.6(-)$ & ND (-) & $\begin{array}{l}\text { Golf course, putting green turf, adjacent to etiolated } \\
\text { area, no symptoms, streaming }(-) \text {, frozen }\end{array}$ & Creeping bentgrass & - \\
\hline $\mathrm{BCCX}$ & $31.8(-)$ & $31.0(-)$ & $31.1(-)$ & $31.3(-)$ & $\begin{array}{l}\text { Golf course, fairway turf, etiolation, streaming (+), } \\
\text { isolated and confirmed Xanthomonas campestris pv. } \\
\text { translucens, frozen }\end{array}$ & Perennial ryegrass & - \\
\hline
\end{tabular}

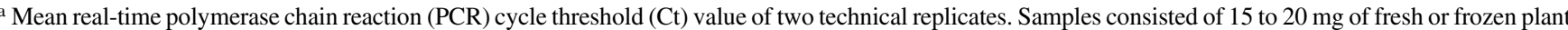
material. All Ct values were derived from two technical replicates of DNA preparations. TaqMan probe was a standard hydrolysis probe with an MGB quencher to inhibit fluorescence. Zen probe was a double quenched TaqMan probe with an additional internal ZEN quencher. ND = not detected due to lack of amplification.

${ }^{\mathrm{b}}$ Isolation of A. avenae. If bacterial infection was suspected, isolation attempts took place using serial dilutions of macerated tissue onto selective media for A. avenae spp.; + represents isolation and identification of A. avenae via $16 \mathrm{~S}$ ribosomal DNA sequencing and - represents no isolation.
} 
G-/3IABkFQ/ was synthesized by Integrated DNA Technologies (http://www.idtdna.com) and incorporates an additional internal ZEN quencher. Real-time PCR assays for detecting A. avenae were performed in $25-\mu 1$ reaction mixtures containing $2 \mu \mathrm{l}$ of template DNA ( 5 to $20 \mathrm{ng} / \mu \mathrm{l}$ ), $20 \mu \mathrm{M}$ each primer, $10 \mu \mathrm{M}$ TaqMan probe, and $2.5 \mu \mathrm{l}$ of TaqMan Universal PCR Master Mix (Applied Biosystems). Each sample was run as three technical replicates. Amplifications were carried out on an ABI Step One Plus real-time PCR system (Applied Biosystems) using the program of an initial denaturing step at

\section{Procedure}

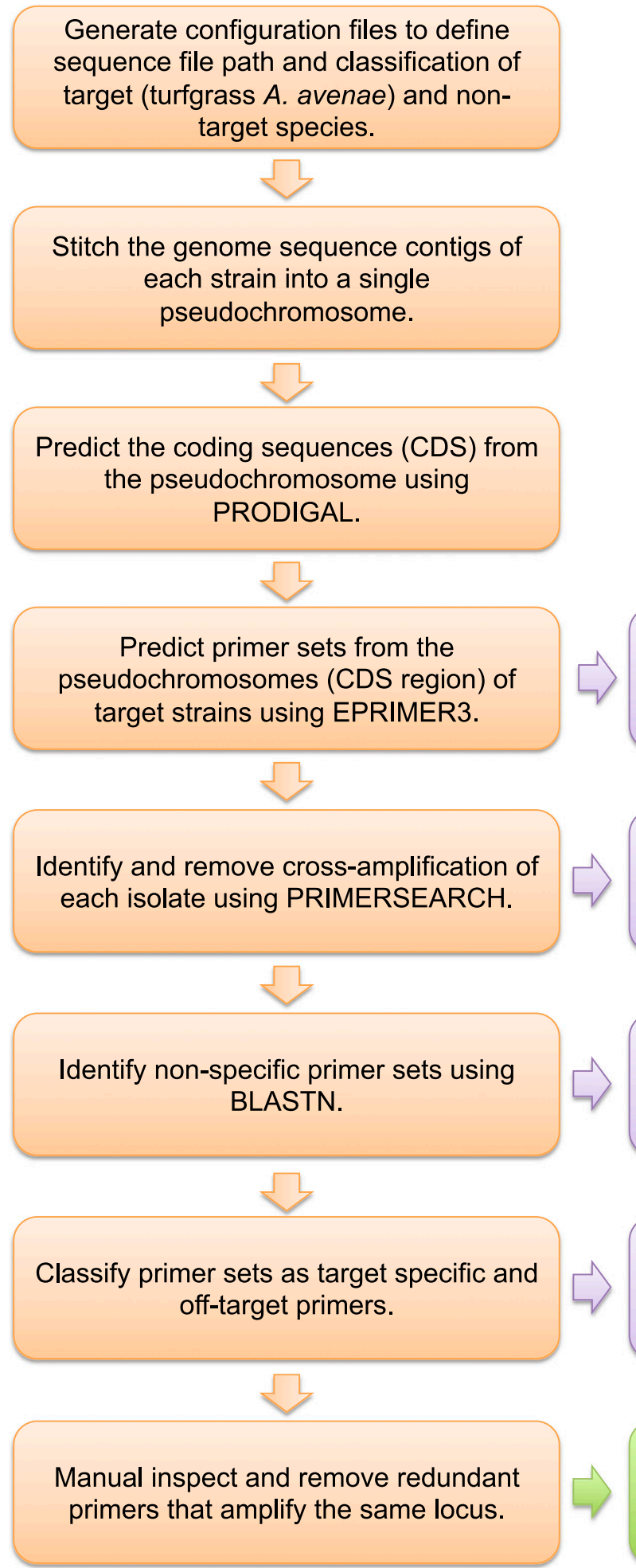

20,000 primers were predicted from each target strain.

Primers that cross-amplify non-target Acidovorax strains were excluded.

Each target strain contained an average of 244 strain-specific primers.

65 primers that specifically amplifies all turfgrass $A$. avenae isolates were predicted.

20 turfgrass $A$. avenae specific primers were produced and used for further experimental validation.

Fig. 1. Flowchart of the primer design procedure and output. 
subject to diagnostics using both a traditional cultural method and the real-time PCR assay developed in this study. The general fitness of the grass samples and presence or absence with the typical BED symptoms were documented. Grass samples were dissected and tested for bacterial streaming using the method described before (Giordano et al. 2010, 2012). Colonies were isolated on Luria-Bertani agar plates and the identification of these colonies was determined by 16S rDNA sequencing. For the real-time PCR diagnostics, grass samples were prepared for DNA extractions. Briefly, 15 to $20 \mathrm{mg}$ of stem and leaf tissue from one to two grass plants was macerated in bead mill homogenizing tubes on a mini bead beater for $1 \mathrm{~min}$ in $1.5 \mathrm{ml}$ of lysis (AP1) buffer (Qiagen). DNA was prepared using the Qiagen DNeasy Plant Mini Kit according to the manufacturer's instructions. Concentrations of DNA were measured using a Nanodrop1000 spectrophotometer (ThermoFisher Scientific) and DNA sample preps were used directly in real-time PCR assays. Real-time assays were conducted according to the specifications indicated above.

\section{Results}

Primer prediction, and PCR validation. A flowchart describing the primer design procedures and outputs is illustrated in Figure 1. The 15 draft genomes of Acidovorax strains were used as input in the primer prediction pipeline with their hosts of origin (i.e., target classification) indicated in Table 1. Contigs of each strain were concatenated into a pseudochromosome and the coding regions of the pseudochromosome from turfgrass-pathogenic A. avenae were subject to primer design. Approximately 20,000 primers were predicted from each target strain (Fig. 1). Two independent rounds of screens for potential cross-amplification of nontarget microorganisms were conducted using PRIMERSEARCH and BLASTN against the local draft genome database, and against all Enterobacteriaceae chromosome and plasmid sequences from GenBank database (ftp://ftp. ncbi.nih.gov/genomes/bacteria), respectively. Each target strain contains approximately 244 strain-specific primers (Fig. 1). After the two rounds of screening, 65 primer sets were predicted as putative discriminatory diagnostic primers for turfgrass-pathogenic A. avenae isolates. After discarding redundant primer sets, 20 pairs remained for further bench experimental testing (Table 2).

Primers that amplified each of the initial two target turfgrass strains (i.e., COLB1 and URI_1) with adequate amplification intensity and little to no amplification of the six nontarget bacterial DNA were subjected to a broader range of isolate testing via conventional PCR. COLB1 and UR_I were used in the initial screen because they belong to each of the two phylogroups of A. avenae, as described previously (Zeng et al. 2017). When using $10 \mathrm{ng}$ of bacterial genomic DNA as template in each PCR, primer sets 0017 and 0019 produced positive PCR results with each of the 22 evaluated target strains, yielding a single band of the expected product size of $200 \mathrm{bp}$ (Fig. 2). Under the predetermined annealing temperature of $60^{\circ} \mathrm{C}$, both primer sets produced faint positive bands with other Acidovorax spp. and subspecies, as well as other bacterial organisms assessed in this study (Fig. 2). Gradient thermal cycling with annealing temperatures ranging from $58^{\circ}$ to $66^{\circ} \mathrm{C}$ determined specific binding to only target DNA in turfgrass isolates to take place at the annealing temperature of $64^{\circ} \mathrm{C}$. At $66^{\circ} \mathrm{C}$, sensitivity of the PCR assay was lost in several of the target isolates (data not shown). Further confirmation of specificity of both the 0017 and 0019 primer sets at $64^{\circ} \mathrm{C}$ showed only amplification of DNA from target isolates, with complete absence of banding from nontarget bacterial isolate DNA (Table 3). Adjustment of the annealing temperature provided the desired specificity of the primers to turfgrass-pathogenic strains of $A$. avenae while limiting nonspecific or phantom banding from the nontarget bacterial hosts (Table 3).

Development of real-time PCR detection of turfgrasspathogenic A. avenae. The two primer sets (0017 and 0019) produced by the bioinformatics pipeline and confirmed with conventional PCR were used to develop real-time PCR detection assays of turfgrass-pathogenic A. avenae. Two probes with different fluorescence chemistries, TaqMan and ZEN, were used in real-time PCR assay development. Detection limits for real-time PCR were determined with 10 -fold serial dilutions of $100 \mathrm{ng}$ of initial A. avenae genomic DNA under conditions described above. The regression curves between the DNA amounts and the Ct values were linear: for $0017 /$ TaqMan, $y=-3.4 x+46\left(R^{2}=0.989\right)$, with a PCR efficiency of $96.84 \%$ and, for $0017 / \mathrm{ZEN}, y=-3.1 x+48\left(R^{2}=0.978\right)$, with a PCR efficiency of $110.17 \%$ (Fig. 3). For 0019/TaqMan, $y=-3.3 x+47\left(R^{2}=\right.$ 0.983 ), with a PCR efficiency of $100.92 \%$ and, for 0019/ZEN $y=-3.5 x$ $+52\left(R^{2}=0.989\right)$, with a PCR efficiency of $93.07 \%$ (Fig. 3). Although the real-time PCR assays could detect concentrations as low as $0.1 \mathrm{pg}$ of pure A. avenae DNA at $\mathrm{Ct}$ values of 35 or higher, we considered samples with $\mathrm{Ct}$ values greater than 31 as $A$. avenae negative based on our preliminary tests to ensure detection specificity, thus eliminating false-positive results. Therefore, the actual detection limit for the realtime PCR assay is between 10 and $100 \mathrm{pg}$ of A. avenae DNA, based on formula of efficiency.

To evaluate the specificity of the real-time PCR assay, we used the developed real-time PCR protocol to detect a panel of 8 turfgrasspathogenic A. avenae and 15 other Acidovorax strains or other bacterial species (Table 5). The eight turfgrass-pathogenic A. avenae strains tested not only represent the two phylogroups of turfgrass A. avenae (group $1=\mathrm{INV}$ and URI1 and group $2=$ the rest of strains) but also represent a large geographical area where the strains were isolated, including the northeast (URI1, URI18, and SF12), Midwest (MOR, INDB2, and INV), mid-Atlantic (MSU14), and southern (COLB1) United States. Both assays (0017 and 0019 primer sets) conducted using the ZEN probe produced positive results with all eight target $A$. avenae strains from turfgrass $(\mathrm{Ct}<31)$ and negative results with all other bacterial species tested $(\mathrm{Ct}>31)$ (Table 5). The assays conducted with the TaqMan probe, however, showed reduced specificity to some of the target isolates, particularly for isolate URI_1 (Table 5). Nonetheless, overall Ct values in all of the assays remained below the determined limit of detection $(\mathrm{Ct}<31)$ for target isolates and above the limit of detection for nontarget organisms.

Detection of turfgrass-pathogenic $A$. avenae from symptomatic turfgrass tissues by real-time PCR validation. In vivo detection of turfgrass-pathogenic A. avenae in symptomatic and asymptomatic turfgrass tissues was assessed using the above real-time PCR assays. A. avenae was positively detected $(\mathrm{Ct}<31)$ from four of four suspected infected samples (HTRC_2012, IL_HIN, HTRC_2013, and LVL12) using all four primer-probe assay combinations (Table 4). In positive detection experiments, $\mathrm{Ct}$ values correlated with visual disease symptoms, intensity of microscopic bacterial streaming, and confirmation of A. avenae via selective medium (King's B) plating and $16 \mathrm{~S}$ rDNA sequencing (i.e., lower $\mathrm{Ct}$ values from heavily infected samples). Negative results $(\mathrm{Ct}>31)$ were obtained from four samples (GLET10, BNTSD1, GLNRM, and BCCX), which were included based on their symptomology and origin. The GLET10 sample displayed symptoms of etiolation and chlorosis; however, it failed to produce signs of bacterial streaming or result in isolation of A. avenae onto selective medium. The BNTSD1 sample was from newly established creeping

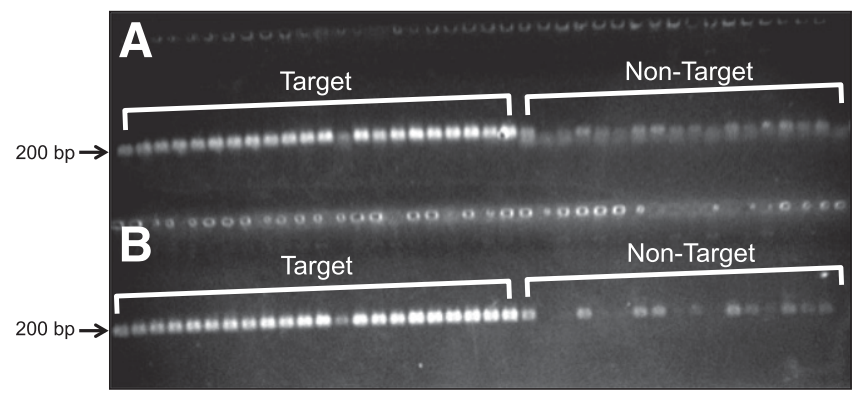

Fig. 2. Polymerase chain reaction amplification of target and nontarget DNA from bacterial isolates using select primer sets designed from whole genome sequences of different Acidovorax spp. All reactions took place using the annealing temperature specified by the primer design pipeline $\left(60^{\circ} \mathrm{C}\right)$. A, Amplification of target isolates (left) and nontarget isolates (right) using the primer set 0017. B, Amplification of target isolates (left) and nontarget isolates (right) using the primer set 0019 . Note the intensified banding on target isolates and subtle banding on nontarget isolates. 
bentgrass seedlings and showed no symptoms or signs of bacterial infection. The GLNRM sample was from an adjacent, asymptomatic area of a golf course putting green displaying no etiolation symptoms. The BCCX sample originated from a perennial ryegrass golf course fairway displaying symptoms of etiolation and decline. Heavy bacterial streaming was detected and isolations of $X$. translucens were achieved; however, no A. avenae was isolated from this sample.

\section{Discussion}

Because BED is a newly emerged disease in turfgrass, efficient and accurate diagnostic tools for the detection of BED pathogens are unavailable. Lack of proper identification and diagnosis of turfgrass-pathogenic A. avenae not only results in delayed accurate management recommendations but also hinders foundational epidemiological research of BED. The techniques employed herein exemplify the utility of draft genome sequences in the development of discriminatory diagnostic primer sets. Manual design of diagnostic primers is not only time consuming but also heavily relies on the availability of known common genes with divergent DNA sequences. For example, previous research in developing diagnostic primers of $A$. citrulli were derived from unique bands amplified from rep-PCR (Bahar et al. 2008) fingerprinting profiles (Ha et al. 2009). This not only limits the selection of available primers but also limits the resolution of the detection technique. Primers derived from these fingerprinting profiles often can differentiate pathogens at the species level (e.g., A. citrulli from A. avenae) (Bahar et al. 2008) but may not be effective in differentiate pathogens at subspecies level. In contrast, genome-based primer prediction methods such as the pipeline employed by this study enlarge the search pool to the coding regions of the entire genome, thus providing a better chance to identify primers with higher discriminatory potentials. Primers developed from this study were able to identify and discriminate a diverse population of turfgrass-pathogenic A. avenae (strains belonging to two distinct phylogroups) (Zeng et al. 2017) from A. avenae pathogenic to other hosts and environmental nontarget bacteria. Furthermore, compared with the alignment-based primer design method such as KPATH (Slezak et al. 2003), the alignment-free primer prediction method used in this study avoids limitations resulting from the need to identify a conserved signature of significant length and common to all targets prior to primer design.

The sets of primers in the output from the Python script pipeline all showed some level of discriminatory ability and specificity to the predefined group of input sequences. Validation of select primers against a wide array of target and nontarget bacterial isolates confirmed specificity of the primer sets, which can separate very closely related strains. Isolates of $A$. avenae from corn, rice, sorghum, and other grass family hosts as well as other Acidovorax spp. were not amplified during PCR assays under optimal primer annealing conditions. Some differences in the intensity of the PCR bands were evident among target turfgrass-pathogenic A. avenae isolates tested, although the vast majority were strongly positive, indicative of a high concentration of amplified product.

An essential aspect of this project was the diagnostic capability of the designed discriminatory primers, and the subsequent development
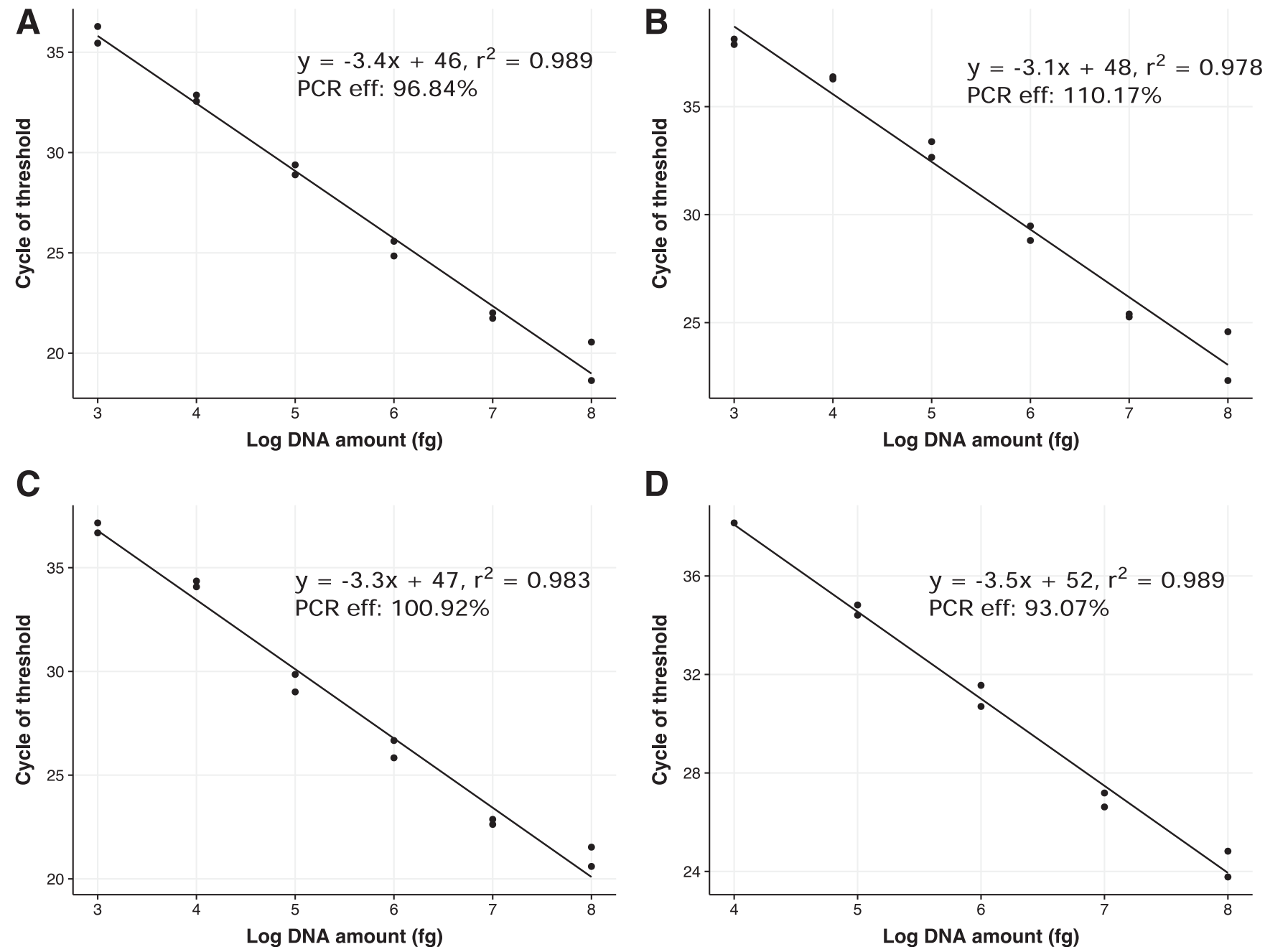

Fig. 3. Real-time polymerase chain reaction (PCR) standard curves of the log of Acidovorax avenae (COLB1) input genomic DNA concentration versus the corresponding cycle threshold (Ct) values. The DNA concentration was $0.1 \mathrm{pg}$ to $100 \mathrm{ng}$. Standard errors are labeled for each data point. A, Standard curve for primer set 0017 with the ZEN probe. B, Standard curve for the primer set 0017 with the TaqMan probe. C, Standard curve for the primer set 0019 with the ZEN probe. D, Standard curve for the primer set 0019 with the TaqMan probe. 
of a reproducible assay to be used in the turfgrass industry for specific detection of BED pathogen A. avenae. Real-time PCR has become a popular diagnostic tool for rapid and sensitive detection and quantification of pathogens in various host samples (Gruber et al. 2001; Hogg et al. 2007; Lievens et al. 2006; Winton et al. 2002). The primers and probes designed in this study allowed us to detect $A$. avenae, the causal agent of BED, in stems and leaves of creeping bentgrass plants.

Specificity and sensitivity are two major factors that need to be taken into consideration during the development of real-time PCR diagnostic assays. Both primer sets (0017 and 0019) in combination with TaqMan and ZEN probes displayed desirable sensitivity and specificity (Table 5). In regards to sensitivity, primers in combination with ZEN probes (average Ct values of 24.2 and 24.7 for 0017 and 0019, respectively) displayed higher sensitivity than TaqMan probes (average $\mathrm{Ct}$ values of 27.4 and 28.0 for 0017 and 0019, respectively) (Table 5), given the same amount of target genomic DNA. In regards to specificity, the 0017/ZEN primer set (Ct value of target organism $=24.72$ and average $\mathrm{Ct}$ value of nontarget organism $=$ 37.27) displayed higher specificity than the 0019/ZEN primer set (average $\mathrm{Ct}$ value of target organism $=24.20$ and average $\mathrm{Ct}$ value of nontarget organism $=35.89)$ (Table 5). Furthermore, compared with the 0017/ZEN primer set, the assays conducted with the 0019/ ZEN primer set also showed higher specificity to some of the target isolates, particularly for isolate URI_1 (Table 5). Thus, we recommend using the 0017/ZEN primer set in the standard diagnostic assay for BED. This specific assay was able to detect as little as $10 \mathrm{pg}$ of pathogenic $A$. avenae genomic DNA in turfgrass samples, equivalent to 1,956 A. avenae cells. This level of detection (detecting $10 \mathrm{pg}$ of target DNA with $\mathrm{Ct}<31$ ) is comparable with the detection levels reported previously for $A$. citrulli (detecting 0.5 to $5 \mathrm{pg}$ of target DNA with Ct between 26 and 30) (Cho et al. 2015). The PCR amplification efficiencies were calculated and provided (Fig. 3), which could be used for the purpose of quantification of the pathogens. The PCR amplification efficiencies of four assays developed were all above 93\% (Fig. 3).
Further validation of the real-time PCR assay involved testing DNA from samples of live and frozen turfgrass stems and leaves collected from symptomatic and asymptomatic turfgrass between 2012 and 2013. Results were compared with visual estimates of disease severity at the time of collection, microscopic observations of bacterial streaming, and isolation onto selective medium and molecular identification via $16 \mathrm{~S}$ rDNA sequencing. The real-time PCR assays detected A. avenae in four of the eight samples. These results agreed not only with the symptoms of etiolation and decline observed among the samples but also with presence of bacterial streaming from tissues determined by microscopic detection and isolation of A. avenae on selective medium from the same four of eight samples. The one exception was the BCCX sample from perennial ryegrass, with $\mathrm{Ct}$ values around 31. This sample showed heavy bacterial streaming from stems and leaves and advanced symptoms of etiolation and decline. However, when isolation measures were taken, only a Xanthomonas pathogen could be recovered and characterized out of the tissue. It is likely that A. avenae is capable of cocolonizing turfgrass plants with Xanthomonas spp. and other pathogenic and nonpathogenic bacterial organisms. Trace amounts of A. avenae within that sample could have resulted in reduced $\mathrm{Ct}$ values and elevated amplification. Roberts et al. (2018) recently reported the isolation and characterization of a Xanthomonas sp. associated with creeping bentgrass etiolation in tandem with A. avenae in the southeastern United States. Therefore, it is likely that this sample of perennial ryegrass could harbor both the suspected primary Xanthomonas causal agent as well as the target organism A. avenae. We only tested this detection method using DNA extracted from bacteria and grass samples as template and have not used fresh plant samples as detection template. When using raw samples (plant extracts), dilution of the sample may be needed before adding it into the PCR to reduce PCR inhibition caused by plant polyphenols and polysaccharides (Schrader et al. 2012).

In summary, we present here a real-time PCR assay that is sensitive and specific for turfgrass-pathogenic $A$. avenae detection. Realtime PCR assays utilizing either the 0017 or 0019 primer set with

Table 5. Isolate name and sensitivity and specificity of select real-time polymerase chain reaction (PCR) primers and probes on DNA preparations from target and nontarget bacterial organisms

\begin{tabular}{|c|c|c|c|c|c|c|c|}
\hline \multirow[b]{3}{*}{ Isolate } & \multicolumn{4}{|c|}{$\begin{array}{c}\text { Real-time PCR results for primer sets } \\
\text { and probe types }{ }^{\mathbf{a}}\end{array}$} & \multirow[b]{3}{*}{ Species $^{\mathbf{b}}$} & \multirow[b]{3}{*}{ Host or source } & \multirow[b]{3}{*}{ Target } \\
\hline & \multicolumn{2}{|c|}{0017} & \multicolumn{2}{|c|}{0019} & & & \\
\hline & TaqMan & ZEN & TaqMan & ZEN & & & \\
\hline INV & 22.8 & 22.1 & 23.6 & 22.7 & Acidovorax avenae & Creeping bentgrass & + \\
\hline URI_1 & 34.1 & 29.7 & 30.3 & 26.4 & A. avenae & Creeping bentgrass & + \\
\hline MOR & 27.9 & 23.7 & 29.8 & 25.5 & A. avenae & Creeping bentgrass & + \\
\hline INDB2 & 28.6 & 24.3 & 30.0 & 25.6 & A. avenae & Creeping bentgrass & + \\
\hline COLB1 & 28.6 & 24.7 & 28.8 & 25.0 & A. avenae & Creeping bentgrass & + \\
\hline MSU_14 & 28.0 & 23.9 & 30.8 & 26.5 & A. avenae & Creeping bentgrass & + \\
\hline URI_18 & 20.9 & 20.4 & 20.8 & 20.2 & A. avenae & Creeping bentgrass & + \\
\hline SF12 & 28.6 & 24.8 & 29.6 & 25.9 & A. avenae & Creeping bentgrass & + \\
\hline AA99-2 & ND & 38.7 & ND & $\mathrm{ND}$ & A. avenae & Maize & - \\
\hline AA81-1 & ND & 38.7 & ND & ND & A. avenae & Maize & - \\
\hline AA78-5 & 35.8 & 34.6 & 36.4 & 37.8 & A. avenae & Vasseygrass & - \\
\hline САT98-1 & 39.5 & 36.5 & ND & ND & A. cattleyae & Orchid & - \\
\hline CIT00-1 & ND & 39.0 & ND & ND & A. citrulli & Melon & - \\
\hline CIT96-9 & 36.7 & 35.3 & 39.2 & 35.6 & A. citrulli & Melon & - \\
\hline CIT92-17 & 36.7 & 36.5 & ND & 39.5 & A. citrulli & Melon & - \\
\hline FAC94-9 & 37.1 & 35.2 & 39.2 & 36.3 & A. facilis & Soil & - \\
\hline FAC96-2 & 34.1 & 32.8 & 34.6 & 33.5 & A. facilis & Soil & - \\
\hline KONJ & ND & $\mathrm{ND}$ & ND & $\mathrm{ND}$ & A. konjaci & Konjac & - \\
\hline MSU_3 & 33.9 & 32.0 & 34.2 & 33.0 & Ochrobactrum pseudogrignonense & Creeping bentgrass & - \\
\hline MSU_6 & 38.6 & 37.1 & 39.8 & 38.4 & Microbacterium binotii & Creeping bentgrass & - \\
\hline MSU_7 & 32.1 & 31.1 & 32.9 & 31.4 & Stenotrophomonas maltophilia & Creeping bentgrass & - \\
\hline $\mathrm{XAN}-1$ & 39.4 & 37.9 & ND & $\mathrm{ND}$ & Xanthomonas translucens pv. poae & Annual bluegrass & - \\
\hline $\mathrm{XAN}-2$ & 34.9 & 32.9 & 35.2 & 33.6 & Xanthomonas translucens & Perennial ryegrass & - \\
\hline
\end{tabular}

${ }^{a}$ Mean real-time PCR cycle threshold value of two technical replicates. TaqMan probe was a standard hydrolysis probe with an MGB quencher to inhibit fluorescence and Zen probe was a double quenched TaqMan probe with an additional internal ZEN quencher. ND = not determined due to lack of amplification.

${ }^{\mathrm{b}}$ Species were originally identified via 16S ribosomal DNA sequencing (Giordano et al. 2012). 
ZEN probe produced the most reliable results, and can be employed in turfgrass diagnostic laboratories for BED detection. This assay allows for the detection of $A$. avenae directly from infected turfgrass plants within $5 \mathrm{~h}$ and, therefore, represents a rapid and simple method to identify BED in the field and evaluate the effectiveness of treatments used for its control. This assay also has many other potentially useful applications in plant breeding, disease quarantine, and a wide array of epidemiological studies.

\section{Acknowledgments}

We thank C. L. Meredith for his technical support.

\section{Literature Cited}

Bahar, O., Efrat, M., Hadar, E., Dutta, B., Walcott, R. R., and Burdman, S. 2008. New subspecies-specific polymerase chain reaction-based assay for the detection of Acidovorax avenae subsp. citrulli. Plant Pathol. 57:754-763.

Cho, M. S., Park, D. H., Ahn, T. Y., and Park, D. S. 2015. Rapid and specific detection of Acidovorax avenae subsp. citrulli using SYBR Green-based realtime PCR amplification of the YD-repeat protein gene. J. Microbiol. Biotechnol. 25:1401-1409.

Giordano, P. R., Chaves, A. M., Mitkowski, N. A., and Vargas, J. M. 2012. Identification, characterization, and distribution of Acidovorax avenae subsp. avenae associated with creeping bentgrass etiolation and decline. Plant Dis. 96:1736-1742.

Giordano, P. R., Vargas, J. M., Detweiler, A. R., Dykema, N. M., and Yan, L. 2010. First report of a bacterial disease on creeping bentgrass (Agrostis stolonifera) caused by Acidovorax spp. in the United States. Plant Dis. 94:922.

Giordano, P. R., Zeng, Q., Dykema, N. M., Detweiler, A. R., and Vargas, J. M. 2015. First report of Xanthomonas translucens causing wilt disease on perennial ryegrass (Lolium perenne) in the United States. Plant Dis. 99:1270.

Gitaitis, R., and Walcott, R. 2007. The epidemiology and management of seedborne bacterial diseases. Annu. Rev. Phytopathol. 45:371-397.

Goto, M. 1964. Nomenclature of bacteria causing bacterial leaf streak and bacterial stripe of rice. Bull. Fac. Agric. Shizuoka Univ. 14:3-10.

Grisham, M., Pan, Y.-B., and Richard, E., Jr. 2007. Early detection of Leifsonia xyli subsp. xyli in sugarcane leaves by real-time polymerase chain reaction. Plant Dis. 91:430-434.

Gruber, F., Falkner, F. G., Dorner, F., and Hammerle, T. 2001. Quantitation of viral DNA by real-time PCR applying duplex amplification, internal standardization, and two-color fluorescence detection. Appl. Environ. Microbiol. 67:2837-2839.

Ha, Y., Fessehaie, A., Ling, K. S., Wechter, W. P., Keinath, A. P., and Walcott, R. R. 2009. Simultaneous detection of Acidovorax avenae subsp. citrulli and Didymella bryoniae in cucurbit seedlots using magnetic capture hybridization and real-time polymerase chain reaction. Phytopathology 99:666-678.

Hogg, A., Johnston, R., and Dyer, A. 2007. Applying real-time quantitative PCR to Fusarium crown rot of wheat. Plant Dis. 91:1021-1028.

Hyatt, D., Chen, G. L., Locascio, P. F., Land, M. L., Larimer, F. W., and Hauser, L. J. 2010. Prodigal: Prokaryotic gene recognition and translation initiation site identification. BMC Bioinf. 11:119.

King, E. O., Ward, M. K., and Raney, D. E. 1954. Two simple media for the demonstration of pyocyanin and fluorescin. J. Lab. Clin. Med. 44:301-307.

Lievens, B., Brouwer, M., Vanachter, A. C., Cammue, B., and Thomma, B. P. 2006. Real-time PCR for detection and quantification of fungal and oomycete tomato pathogens in plant and soil samples. Plant Sci. 171:155-165.

López, M. M. R., Roselló, M., and Palacio-Bielsa, A. 2010. Diagnosis and detection of the main bacterial pathogens of stone fruit and almond. J. Plant Pathol. 92:S1.57-S1.66.

Mitkowski, N. A., Browning, M., Basu, C., Jordan, K., and Jackson, N. 2005. Pathogenicity of Xanthomonas translucens from annual bluegrass on golf course putting greens. Plant Dis. 89:469-473.

Postnikova, E., and Schaad, N. W. 2002. Phylogenetic studies of corn and rice strains of Acidovorax avenae subsp. avenae by DNA/DNA hybridization. (Abstr.) Phytopathology 92:S66.
Pritchard, L., Holden, N. J., Bielaszewska, M., Karch, H., and Toth, I. K. 2012a. Alignment-free design of highly discriminatory diagnostic primer sets for Escherichia coli O104:H4 outbreak strains. PLoS One 7:e34498.

Pritchard, L., Humphris, S., Saddler, G. S., Parkinson, N. M., Bertrand, V., Elphinstone, J. G., and Toth, I. K. 2012b. Detection of phytopathogens of the genus Dickeya using a PCR primer prediction pipeline for draft bacterial genome sequences. Plant Pathol. 62:587-596.

Rice, P., Longden, I., and Bleasby, A. 2000. EMBOSS: The European Molecular Biology Open Software Suite. Trends Genet. 16:276-277.

Roberts, J. A., Ma, B., Tredway, L. P., Ritchie, D. F., and Kerns, J. P. 2018. Identification and pathogenicity of bacteria associated with etiolation and decline of creeping bentgrass golf course putting greens. Phytopathology 108:23-30.

Roberts, J. A., Ritchie, D. F., and Kerns, J. P. 2016. Plant growth regulator effects on bacterial etiolation of creeping bentgrass putting green turf caused by Acidovorax avenae. Plant Dis. 100:577-582.

Schaad, N. W., Berthier-Schaad, Y., and Knorr, D. 2007. A high throughput membrane BIO-PCR technique for ultra-sensitive detection of Pseudomonas syringae pv. phaseolicola. Plant Pathol. 56:1-8.

Schaad, N. W., Opgenorth, D., and Gaush, P. 2002. Real-time polymerase chain reaction for one-hour on-site diagnosis of Pierce's disease of grape in early season asymptomatic vines. Phytopathology 92:721-728.

Schena, L., Nigro, F., Ippolito, A., and Gallitelli, D. 2004. Real-time quantitative PCR: A new technology to detect and study phytopathogenic and antagonistic fungi. Eur. J. Plant Pathol. 110:893-908.

Schrader, C., Schielke, A., Ellerbroek, L., and Johne, R. 2012. PCR inhibitors occurrence, properties and removal. J. Appl. Microbiol. 113:1014-1026.

Shakya, D., and Chung, H.-S. 1983. Detection of Pseudomonas avenae in rice seed. Seed Sci. Technol. 11:583-587.

Slezak, T., Kuczmarski, T., Ott, L., Torres, C., Medeiros, D., Smith, J., Truitt, B., Mulakken, N., Lam, M., Vitalis, E., Zemla, A., Zhou, C. E., and Gardner, S. 2003. Comparative genomics tools applied to bioterrorism defence. Brief. Bioinf. 4:133-149.

Song, W., Kim, H., Hwang, C., and Schaad, N. W. 2004. Detection of Acidovorax avenae ssp. avenae in rice seeds using BIO-PCR. J. Phytopathol. 152:667-676.

Song, W.-Y., Kim, H.-M., and Schaad, N. W. 2002. PCR primers for detection and identification of plant pathogenic species, subspecies, and strains of Acidovorax. United States Department of Agriculture patents.

Stead, D., Stanford, H., Aspin, A., Heeney, J., Iacobellis, N., Collmer, A. Hutcheson, S., Mansfield, J., Morris, C., and Murillo, J. 2003. Current status of some new and some old plant pathogenic Pseudomonads. Pages 561-572 in: Presentations 6th Int. Conf. Pseudomonas syringae Pathovars and Related Pathogens, Maratea, Italy. Kluwer Academic Publishers.

Sundin, G. W., Castiblanco, L. F., Yuan, X., Zeng, Q., and Yang, C. H. 2016. Bacterial disease management: challenges, experience, innovation and future prospects. Mol. Plant Pathol. 17:1506-1518.

Walcott, R., Fessehaie, A., and Castro, A. 2004. Differences in pathogenicity between two genetically distinct groups of Acidovorax avenae subsp. citrulli on cucurbit hosts. J. Phytopathol. 152:277-285.

Walcott, R., and Gitaitis, R. 2000. Detection of Acidovorax avenae subsp. citrulli in watermelon seed using immunomagnetic separation and polymerase chain reaction. Plant Dis. 84:470-474.

Walcott, R. R., Langston, D. B., Sanders, F. H., and Gitaitis, R. D. 2000 Investigating intraspecific variation of Acidovorax avenae subsp. citrull using DNA fingerprinting and whole cell fatty acid analysis. Phytopathology 90:191-196.

Wang, J., Jacobs, J. L., Byrne, J. M., and Chilvers, M. I. 2015. Improved diagnoses and quantification of Fusarium virguliforme, causal agent of soybean sudden death syndrome. Phytopathology 105:378-387.

Winton, L. M., Stone, J. K., Watrud, L. S., and Hansen, E. M. 2002. Simultaneous one-tube quantification of host and pathogen DNA with real-time polymerase chain reaction. Phytopathology 92:112-116.

Zeng, Q., Wang, J., Bertels, F., Giordano, P., Chilvers, M. I., Huntley, R. B. Vargas, J. M., Sundin, G. W., Jacobs, J. L., and Yang, C. H. 2017. Recombination of virulence genes in divergent Acidovorax avenae strains that Infect a common host. Mol. Plant-Microbe Interact. 30:813-828. 